\title{
Correction to: Characterization of hydrothermal alteration along geothermal wells using unsupervised machine-learning analysis of X-ray powder diffraction data
}

\author{
Kazuya Ishitsuka ${ }^{1}\left(\right.$ Hiroki Ojima $^{2} \cdot$ Toru $^{\text {Mogi }}{ }^{3} \cdot$ Tatsuya Kajiwara $^{4} \cdot$ Takeshi Sugimoto $^{4} \cdot$ Hiroshi Asanuma $^{5} \mathbb{D}$
}

Published online: 29 October 2021

(c) The Author(s) 2021

Correction to: Earth Science Informatics

https://doi.org/10.1007/s12145-021-00694-3

In the original published version of this article, the affiliation of first author Kazuya Ishitsuka, "Division of Sustainable Resources Engineering, Hokkaido University, Kita-ku, Sapporo, Japan" should be included under the affiliation section since the said affiliations was Kazuya Ishitsuka's previous affiliation. An information has been placed on the first page of the original published article to note this change.

The original article has been corrected.

Publisher's Note Springer Nature remains neutral with regard to jurisdictional claims in published maps and institutional affiliations.

The original article can be found online at https://doi.org/10.1007/ s12145-021-00694-3.

Kazuya Ishitsuka

ishitsuka.kazuya.4w@kyoto-u.ac.jp

1 Department of Urban Management, Kyoto University, Nishikyo-ku, Kyoto, Japan

2 Cooperative Program for Resources Engineering, Hokkaido University, Kita-ku, Sapporo, Japan

3 Volcanic Fluid Research Center, Tokyo Institute of Technology, Meguro-ku, Tokyo, Japan

4 Geothermal Engineering Co., Ltd, Takizawa, Iwate, Japan

5 Fukishima Renewable Energy Institute, National Institute of Advanced Industrial Science and Technology, Koriyama, Fukushima, Japan 